\title{
Factors contributing to the separation of endodontic files
}

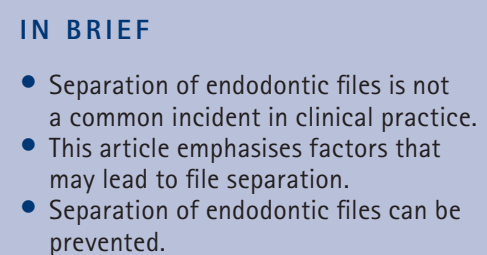
prevented.

\author{
A. A. Madarati, ${ }^{1}$ D. C. Watts ${ }^{2}$ and A. J. E. Qualtrough ${ }^{3}$
}

prevented.

Cleaning and shaping of the root canal system is essential for successful endodontic treatment. However, despite improvements in file design and metal alloy, intracanal file separation is still a problematic incident and can occur without any visible signs or permanent deformation. Only a few studies have reported high success rates of fractured file removal using contemporary techniques. Conflicting results have been reported regarding the clinical significance of retaining separated files within root canals. An understanding of the mechanisms of, factors contributing to, file fracture is necessary to reduce the incidence of file separation within root canals. This article reviews the factors that are of utmost importance and in light of these, preventive procedures and measures are suggested.

\section{INTRODUCTION}

Successful endodontic treatment depends on a series of sequential procedures including cleaning and shaping of the root canal system. Procedural errors such as ledging, zipping, canal perforation and apex transportation can occur during root canal instrumentation. However, separation of endodontic instruments (SEF) is a problematic incident. Such an error prevents the achievement of efficient cleaning and shaping, which in turn can result in under-filling of the root canal. Eventually the treated case may end in failure. Even with NiTi files, which are more sophisticated, stronger and more flexible than stainless steel instruments, ${ }^{1}$ failure is still a concern because these instruments can undergo fracture within their elastic limit and without any visible signs of previous permanent deformation. ${ }^{2,3}$ Conflicting results have been reported regarding the

${ }_{1 *}$ Doctoral Researcher in Endodontology; ${ }^{2}$ Professor, Biomaterials Science; ${ }^{3}$ Senior Lecturer, Honorary Consultant in Restorative Dentistry, School of Dentistry, University of Manchester, Higher Cambridge Street, Manchester, M15 6FH

${ }^{*}$ Correspondence to: Dr Ahmad Madarati

Email:ahmad.madarati@hotmail.co.uk

\section{Refereed Paper}

Accepted 28 January 2008

DOI: $10.1038 /$ bdj.2008.152

${ }^{\oplus}$ British Dental Journal 2008; 204: 241-245 clinical significance of fractured files remaining within treated root canals. However, a reduction in healing of perapical lesions when fractured fragments involved teeth with necrotic pulp or perapical lesions has been reported. ${ }^{4}$ Few studies have reported a high success in removing SEF using the most contemporary techniques. ${ }^{5,6}$ Success is less likely when fragments are located in the apical third or beyond the root canal curvature, especially those with severe curves. ${ }^{5-8}$ In high risk cases, with potential complications such as root perforation or root fracture, removal of fractured instruments is not recommended. ${ }^{9}$ Clinicians should evaluate each case individually and consider all aspects of management of SEF. Preventive procedures related to SEF are of utmost importance. In light of this, a good understanding of the mechanisms and factors contributing to file fracture is essential. This article aims to review factors that contribute to SEF. Since many general dental practitioners and endodontists depend on rotary instruments for cleaning and shaping of the root canals, most of this paper will relate to rotary endodontic instruments.

\section{Operator proficiency}

There is no doubt that both training and adequate skills are imperative for all dental procedures and particularly so in endodontics. Many guidelines have been suggested for the prevention of SEF. ${ }^{10}$ Most are related to the operator, including:

- Instruments should be examined, before and after use, to make certain that blades are regularly aligned

- Instruments should not be used in dry canals

- Files should be used according to the manufacturer's instructions and excessive forces should be avoided.

There is a variety of protocols for root canal instrumentation. Experience of file separation was found to differ not only between different dental practitioners, but also at different times for the same practitioner. ${ }^{11,12}$ Preclinical training for mastering instrumentation and improving operator competence through learning and experience are crucial for the avoidance of rotary file separation and reducing the incidence of instrument locking and deformation. ${ }^{11,13,14}$ A recent clinical study of endodontists from four different countries showed that the most important influence on defect occurrence was the operator. ${ }^{15}$ This was attributed to their clinical skills or their decision either to use instruments for a specific number of times or until defects were evident. 


\section{ROOT CANAL ANATOMY}

\section{A. The angle of canal curvature}

It is generally accepted that the more complicated the root canal morphology, the greater the risk of endodontic instrument breakage. A higher prevalence of SEF has been reported in molars ${ }^{16,17}$ particularly in the mesial roots of mandibular molars. ${ }^{6,7}$ Also, the risk of SEF in the apical third of the canal is higher when compared with coronal and middle thirds. ${ }^{16}$ Files undergo greater fatigue as the curvature increases and the contact surface with the dentinal walls is greater since most curved canals are narrow. Clinically, fatigue of an instrument may be related to the degree of instrument flexure when placed in a curved root canal. When the curvature of canals is pronounced, the cyclical fatigue of the instrument is greater and thus its life expectancy is lower. ${ }^{2}$

\section{B. The radius of canal curvature}

The parameters of the angle and the radius of curvature are independent in such a way that even if two canals have the same angle of curvature they may have different radii of curvature, which indicates that some curves are sharper than others ${ }^{18}$ (Fig. 1). Thus, the radius of canal curvature is more important than the curvature angle itself. It has been reported that the rate of file separation increases as the radius of curvature decreases. ${ }^{19}$ When several variables, including those related to root canal anatomy, are considered, the radius of curvature is the most significant factor in rotary file failure. ${ }^{20}$

\section{Metal alloy}

An understanding of the characteristics of endodontic file materials is important when failure is considered. The properties of endodontic instruments differ from each other depending, in particular, on their metallic composition. Also the manner and efficiency of cutting dentine are not the same. As a result, their resistance to defect formation and fracture differ. Stainless steel reamers and files were found to be preferable to carbon steel instruments in this respect. ${ }^{10}$ NiTi files have been reported to be three times stronger, more flexible and have superior resistance to torsional fracture compared with stainless steel files. ${ }^{1}$

\section{SIZE AND CROSS-SECTIONAL SHAPE}

Cross-sectional shape determines the bulk of the file and the contact area between the file and dentinal walls, as well as its cutting efficiency. The greater the area of file contacting the dentinal walls, the greater the quantity of cut dentine. Consequently there is greater friction and a fatigued file has a reduced life span. ${ }^{21}$ There are two types of endodontic file cross-section. While active instruments have active cutting blades, passive instruments have a radial land between the cutting edge and flute. The radial land contacts the canal wall on its entire surface. In general, active instruments cut more effectively and aggressively. Passive instruments perform a scraping or burnishing rather than a real cutting action, and remove dentine more slowly. ${ }^{22}$ The size of the rotary file determines how many times it should be used. ${ }^{23}$ As the diameter of the file increases, the force needed to unwind or fracture also increases. ${ }^{24}$ However, clinically large instruments that are used many times should be reused with great care or be discarded. Instruments of a rhomboid-shaped crosssectional design were reported to be less resistant to bending force compared with those of square cross-section..$^{25}$ Also, Sshaped files and H-type cross-section were less resistant to failure, compared with those of a triangular cross-sectional shape. Although this was explained by the flexibility and bulk point of view, the contact surface should be considered especially in clinical cases, as some cross-sectional shapes have greater areas of contact than others. Clinically, the greater the file taper, the greater the contact surface with dentine, and the less resistance to fracture. ${ }^{3,26,27}$ Recently, the mechanical properties of endodontic files have been mathematically studied using the finite element analysis method (FEA). It has been shown that as the area of the inner core of the crosssection increased, the model was more torque-resistant. ${ }^{28}$ Berutti et al. compared torsional and bending stresses between ProTaper and ProFile rotary systems. They concluded that:

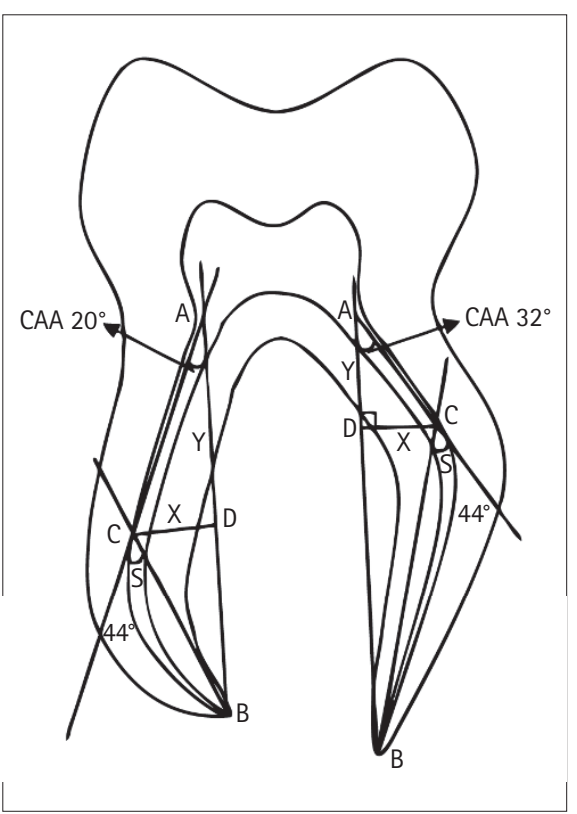

Fig. 1 Two root canals of a molar have the same Shneider canal curvature, but measured different angles using the Access Canal Angles (CAA) (Adopted from Gunday $\mathrm{M}^{18}$ )

- ProTaper, being stronger and less elastic, may be more appropriate for use in narrow and curved canals during the initial phase of shaping

- The ProFile system, being elastic but not as strong, may be more appropriate for wide and curved canals in the final phase of shaping.

\section{Frequency of use}

There is no agreement in the literature regarding the number of times of use related to fracture. SEF is a complex multi-factorial clinical problem, thus one can not expect or recommend how many cases or even canals may be prepared by a file. ${ }^{15}$ Small hand instruments were recommended not to be used more than twice. ${ }^{10}$ However, even the smallest instruments cannot be used many times without fear of fracture specially where there is visible distortion. ${ }^{29}$ Yared et al. found that Profile instruments could be used up to ten times in simulated canals without fracture..$^{30}$ In a follow-up study, these instruments were pronounced safe in up to four molars. ${ }^{31}$ It is clear that the frequency of use in simulated canals is different compared to that in extracted teeth. A recent clinical study has indicated that ProTaper rotary files may be safely reused at least four times. ${ }^{23}$ Nevertheless, it is still very difficult clinically 
to recommend a specific number of times of use. Individual canals are not anatomically the same as well as all other factors that influence file separation. It is difficult to predict when an instrument will fracture. Consequently, single use has been recommended for absolute safety. ${ }^{32}$ Arens et al. (2003) examined a total of 786 clinically single used rotary files. ${ }^{32}$ Fourteen percent of instruments showed various defects and seven files $(0.9 \%)$ fractured. It was concluded that for absolute safety a single-use approach should be followed. However, it was obvious that even with single use, endodontic files still undergo defects (Fig. 2). Moreover, files were inspected at $\mathrm{x} 16$ magnification, which is not sufficient to show all microstructural defects that may be observed by SEM. These defects are stress-concentration points at which microcracks can initiate and later propagate resulting in file separation. ${ }^{17,33}$ When using SEM to study separated endodontic files, the question of the clinical usability of rotary NiTi files remains unanswered. ${ }^{29}$ It is almost that endodontic files fracture not because of how many times they are used, but rather how they are used.

\section{Sterilisation}

It is well accepted that thermo-cycling may result in metal fatigue. However, there is no consensus in the literature regarding the effects of the specific type of thermo-cycling during sterilisation of endodontic instruments. Some studies have shown that sterilisation does not adversely affect endodontic instruments. ${ }^{34,35}$ Although others reported slight or significant adverse effects of sterilisation, it was confirmed that these adverse effects are not of clinical importance..$^{21,36}$ On the other hand, few studies have reported increased resistance to failure after endodontic files are subjected to sterilisation procedures. ${ }^{37}$ However, most studies did not simulate the clinical situation. Thus, the impact of multiple usages of endodontic files should be considered. Nevertheless, recently the UK Chief Dental Officer has recommended single use of endodontic files. This is due to the concern that effective disinfection is not possible with respect to prion disease.
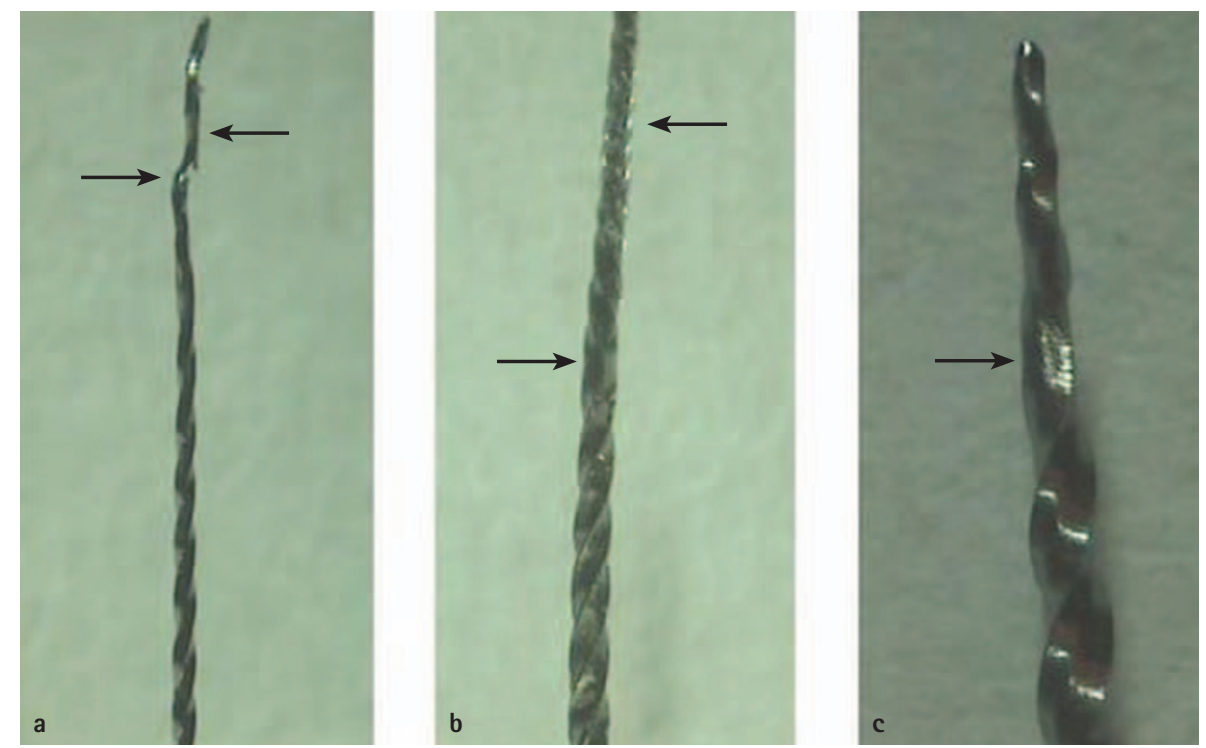

Fig. 2 Defects (arrows) on K-files size 10 (A) and 15 (B) and F2 ProTaper rotary file (C) after a single use

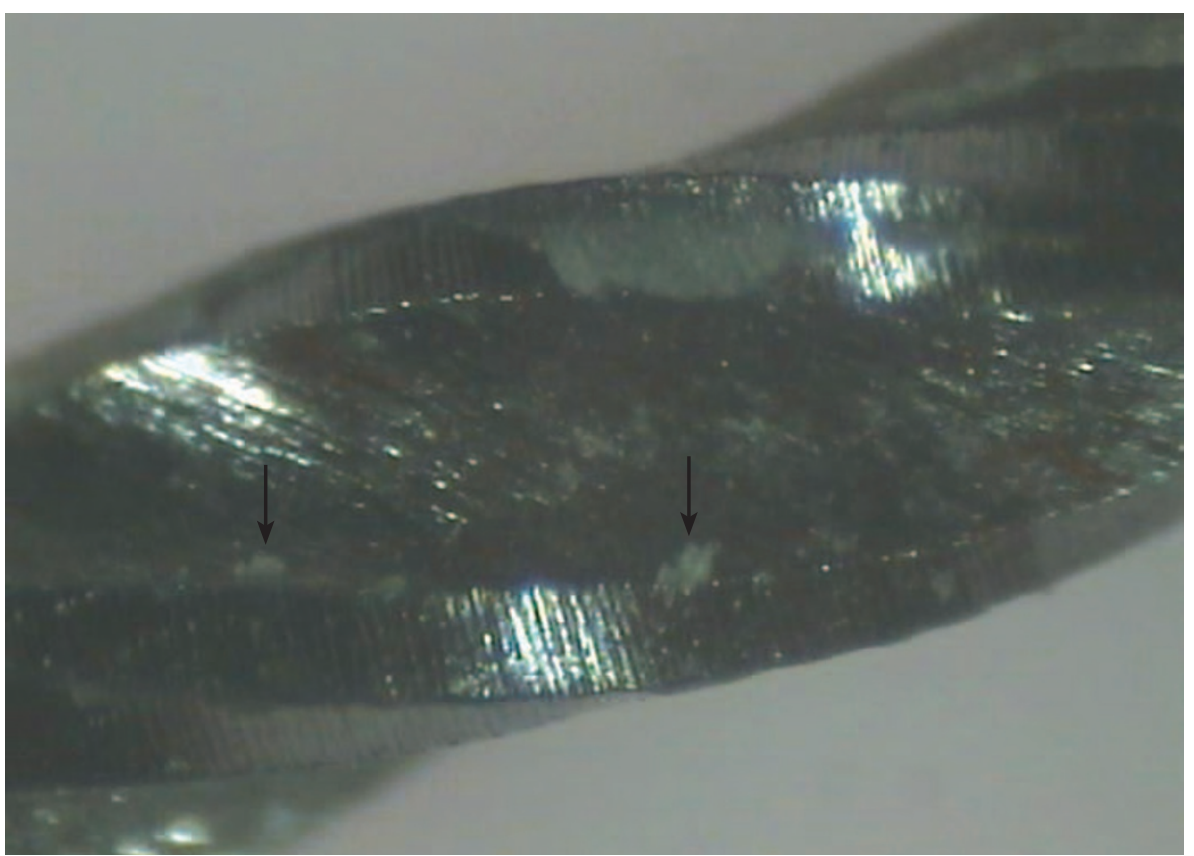

Fig. 3 Dentine chips (arrows) embedded in the bulk of size 25 rotary file (04 ProFile)

Further studies are required to evaluate the influence of such recommendation on reducing SEF in dental practice.

\section{Torque}

During instrumentation, files tip or flutes may engage a portion of the canal smaller than their diameter. Hence, instruments tend to lock or screw into the canal walls and the torque rises rapidly leading the file to be subjected to high levels of stress. The torque generated during instrumentation of small canals is higher than that in large canals. ${ }^{38}$ Also, as the file diameter increases, the torque (force) needed to begin unwinding or to fracture also increases. ${ }^{24}$ If the torque reaches a critical level, the instrument undergoes structural failure resulting in separation. When a high torque is used, the instrument is very active and the incidence of instrument locking and consequent deformation and separation tends to increase. ${ }^{3}$ Sometimes instruments become less active and the operator may force the instrument into the canal, leading to deformation and separation. With respect to root canal curvature, smaller files fail at less torque, as do files in more acutely curved canals. ${ }^{20}$ It has been reported that instruments used with low-torque motors $(<1 \mathrm{~N} / \mathrm{cm})$ 
are more resistant to fracture than those used with high-torque motors $(>3 \mathrm{~N}$ / $\mathrm{cm}) .^{3}$ Therefore, practitioners should use electric motors set at low torque levels during root canal preparation.

\section{Speed of rotation}

Most manufacturers suggest using rotary files at speeds ranging from 150 to 350 rpm. A higher rate of SEF was reported when rotating at high speeds (300-350 rpm). ${ }^{39}$ Also the time for rotary instruments to fail significantly decreases as rotation increases. ${ }^{40}$ On the other hand, some studies showed no effect of different rotation speeds on the incidence of rotary file fracture. However, it should be noted that file fracture was considered as a main criterion for failure of instruments while deformed instruments should be considered as failed also. ${ }^{41}$ Different methodologies were used, which may explain the different conclusions reported. However, it is imperative that clinicians always adhere to the speed recommended by the manufacturer for each rotary system and sometimes for each specific file.

\section{Manufacturing procedures}

Endodontic instruments may fracture even after a single use. Some studies have reported the existence of manufacturing defects on the surface of new endodontic instruments. Hence, visual examination before inserting files into canals is required. Cold work and heat treatments are important manufacturing procedures that should be controlled during file manufacture. ${ }^{42}$ Also, debris of metal origin which cause stress-concentration should be taken into consideration. ${ }^{12} \mathrm{~A}$ high incidence of machining defects on the surface of NiTi files was shown by SEM observation. ${ }^{12}$ These defects cause microcrack formation, which in turn propagate during instrumentation and eventually the file fails in fatigue mode. Oxide particles serve as nucleating sites for micro-voids, leading to dimpled ruptures. ${ }^{43}$ Consequently, high metallurgical quality of NiTi alloy, to avoid initiating of micro-cracks, and innovative manufacturing strategies are essential. The lifetime of endodontic files may be increased by different procedures. Application of thermal treatments (recovery) before machining was found to decrease the work-hardening of the alloy. ${ }^{42}$ Electro-polishing was recommended to reduce machining damage on the file surface. ${ }^{42,43}$ However, a recent study showed that such measures did not inhibit the development of microfractures in EndoSequence rotary files. ${ }^{44}$ Considerable care is necessary to avoid degrading the cutting efficiency of fluted regions..$^{42,43}$ Nevertheless, a promising approach is the use of ion implantation to modify surface properties of NiTi instruments.

\section{INSTRUMENTATION PROCEDURES}

\section{A. Pre-flaring}

It is accepted that provision of a glide path should facilitate the work of subsequent instruments which can smoothly clean and shape root canals. Preflaring of root canal with hand files was reported to allow a significantly greater number of uses of rotary files before fracture occurred. ${ }^{45}$ There are two main advantages when initial manual preflaring is established. ${ }^{45}$ Firstly, torsional stress is drastically reduced because the canal width becomes at least equal to the diameter of the tip of the instrument is used. Secondly, preflaring creates an understanding of the root canal anatomy and allows a glide path for the instrument tip.

\section{B. Instrumentation sequence}

It is essential that the instrumentation sequence of a specific technique is not neglected. A sequence including various tapers is safer compared to a single taper use. ${ }^{46}$ Although it requires a greater number of instruments to prepare canals, each file will undergo less stress and consequently a greater life span. The concept of hybrid instrumentation has been recently introduced. It is believed that a combination of files of different systems and the use of different instrumentation techniques to manage individual clinical situations can reduce the risk of file separation. ${ }^{22}$

\section{Irrigation and irrigants}

Lubrication, in general, decreases friction between solid objects so few defects occur. In endodontics it is imperative to use files in wet canals to facilitate cleaning and shaping. ${ }^{10}$ However, conflicting results have been reported regarding the adverse effects of different irrigants and even different concentrations of the same irrigants on mechanical properties of endodontic files. ${ }^{47,48}$ It is important to stress that most studies have shown different degrees of corrosion on the surface of instruments. These can be considered as weak areas at which further defects, such as microcracks, may be initiated. Clinically, sodium hypochlorite $(\mathrm{NaOCl})$ is one of the most commonly used irrigants and its effect on endodontic files has been widely investigated. The integration of this irrigant with other factors may result in magnitude metal fatigue and later in file separation. A recent study showed that files immersed in $5.25 \%$ of sodium hypochlorite had significantly less resistance to fracture when they underwent cyclic fatigue. ${ }^{49}$

\section{Dentinal debris}

The possible effect of dentine chips embedded in the microstructure of failed endodontic instruments should be considered (Fig. 3). One study showed that dentinal debris was wedged mostly in narrow radial, land-type regions and less on the convex flute surfaces of used ProTaper files. ${ }^{50}$ For used ProFile instruments, dentinal debris was wedged mostly in the metal rollover and on concave flute surfaces. These dentinal chips can cause concentration of stresses that contributes to the clinical failure of NiTi rotary instruments. It was hypothesised that clinical fracture of nickel-titanium rotary instruments is largely caused by a single overload incident during instrumentation, rather than the result of significant alloy fatigue. Such overloading can be caused by local embedment of dentinal chips in machining grooves. ${ }^{43}$

\section{Type of handpieces}

Air-driven and electric handpieces are both currently available for use with rotary nickel-titanium files. As indicated above, usage of electric hand pieces enable clinicians to control the torque applied on endodontic files in individual situations.

\section{CONCLUSION}

In metallurgic failure, the interaction of the environment, stress and an alloy can 
be quite complex. In this respect, many factors are involved in the failure of endodontic instruments and it is difficult to specify only one factor. In reality, separation of endodontic files is a complex process and when one tries to explain the mechanism of instrument failure, all factors should be considered. Some of these are out of the practitioner's control, and one can not predict when fracture will occur. However, intracanal file separation depends, most of the time, on how the instruments work within root canals. An understanding of instrumentation concepts, especially how files cut the dentinal structure and how they fatigue, is essential in prolonging the life span and minimising the risk of file separation. The following are some important recommendations to be considered to minimise the incident of endodontic file separation:

1. Appropriate training before using files of new design

2. Understanding of root canal anatomy and establishing of glide path before cleaning and shaping

3. Examination of new files as some defects can occur while being manufactured

4. Examination of files during treatment regularly even with a single use

5. Use of magnification for file examination as some defects can not be seen by naked eye

6. Adherence to the manufacturer's instructions.

1. Walia H M, Brantley W A, Gerstein H. An initial investigation of the bending and torsional properties of Nitinol root canal files. J Endod 1988; 14: 346-351.

2. Pruett J P, Clement D J, Carnes D L, Jr. Cyclic fatigue testing of nickel-titanium endodontic instruments. J Endod 1997; 23: 77-85.

3. Gambarini G. Cyclic fatigue of nickel-titanium rotary instruments after clinical use with low- and high-torque endodontic motors. J Endod 2001: 27: 772-774

4. Spili P, Parashos P, Messer H H. The impact of instrument fracture on outcome of endodontic treatment. J Endod 2005; 31: 845-850.

5. Suter B, Lussi A, Sequeira P. Probability of removing fractured instruments from root canals. Int Endod J 2005; 38: 112-123.

6. Ward J R, Parashos P, Messer H H. Evaluation of an ultrasonic technique to remove fractured rotary nickel-titanium endodontic instruments from root canals: an experimental study. J Endod 2003; 29: 756-763.

7. Hulsmann M, Schinkel I. Influence of several factors on the success or failure of removal of fractured instruments from the root canal. Endod Dent Traumatol 1999; 15: 252-258.
8. Shen Y, Peng B, Cheung G S. Factors associated with the removal of fractured NiTi instruments from root canal systems. Oral Surg Oral Med Oral Pathol Oral Radiol Endod 2004; 98: 605-610.

9. Souter N J, Messer H H. Complications associated with fractured file removal using an ultrasonic technique. J Endod 2005; 31: 450-452.

10. Grossman LI. Guidelines for the prevention of fracture of root canal instruments. Oral Surg Oral Med Oral Pathol 1969; 28: 746-752.

11. Mandel E, Adib-Yazdi M, Benhamou L M, Lachkar T, Mesgouez C, Sobel M. Rotary Ni-Ti profile systems for preparing curved canals in resin blocks: influence of operator on instrument breakage. Int Endod J 1999; 32: 436-443.

12. Marending M, Lutz F, Barbakow F. Scanning electron microscope appearances of Lightspeed instruments used clinically: a pilot study. Int Endod J 1998; 31: 57-62

13. Yared G M, Dagher F E, Machtou P, Kulkarni G K. Influence of rotational speed, torque and operator proficiency on failure of Greater Taper files. Int Endod J 2002; 35: 7-12.

14. Yared G, Bou Dagher F, Kulkarni K. Influence of torque control motors and the operator's proficiency on ProTaper failures. Oral Surg Oral Med Oral Pathol Oral Radiol Endod 2003; 96: 229-233.

15. Parashos P. Gordon I, Messer H H. Factors influencing defects of rotary nickel-titanium endodontic instruments after clinical use. J Endod 2004; 30: 722-725.

16. Iqbal M K, Kohli M R, Kim J S. A retrospective clinical study of incidence of root canal instrument separation in an endodontics graduate program: a PennEndo database study. J Endod 2006; 32: 1048-1052.

17. Peng B, Shen $Y$, Cheung G S, Xia T J. Defects in ProTaper S1 instruments after clinical use: longitudinal examination. Int Endod J 2005; 38: 550-557.

18. Gunday M, Sazak H, Garip Y. A comparative study of three different root canal curvature measurement techniques and measuring the canal access angle in curved canals. J Endod 2005; 31: 796-798.

19. Patino PV, Biedma B M, Liebana C R, Cantatore G, Bahillo J G. The influence of a manual glide path on the separation rate of NiTi rotary instruments. J Endod 2005; 31: 114-116.

20. Booth J R, Scheetz J P, Lemons J E, Eleazer P D. A comparison of torque required to fracture three different nickel-titanium rotary instruments around curves of the same angle but of different radius when bound at the tip. J Endod 2003: 29: 55-57.

21. Roulet J F. Dynamic fracture of conventional endodontic instruments versus experimental files. J Endod 1983; 9: 12-16.

22. Walsch $\mathrm{H}$. The hybrid concept of nickel-titanium rotary instrumentation. Dent Clin North Am 2004; 48: 183-202.

23. Wolcott S, Wolcott J, Ishley D, Kennedy W et al. Separation incidence of protaper rotary instruments: a large cohort clinical evaluation. J Endod 2006; 32: 1139-1141.

24. Guilford W L, Lemons J E, Eleazer P D. A comparison of torque required to fracture rotary files with tips bound in simulated curved canal. J Endod 2005; 31: 468-470.

25. Schafer E, Tepel J. Relationship between design features of endodontic instruments and their properties. Part 3. Resistance to bending and fracture. J Endod 2001; 27: 299-303.

26. Wolcott J, Himel V T. Torsional properties of nickeltitanium versus stainless steel endodontic files. J Endod 1997; 23: 217-220.

27. Haikel $Y$, Serfaty R, Bateman G, Senger B, Allemann C. Dynamic and cyclic fatigue of engine-driven rotary nickel-titanium endodontic instruments. J Endod 1999; 25: 434-440.

28. Xu X, Eng M, Zheng Y, Eng D. Comparative study of torsional and bending properties for six models of nickel-titanium root canal instruments with different cross-sections. J Endod 2006; 32: 372-375.
29. Svec T A, Powers J M. The deterioration of rotary nickel-titanium files under controlled conditions. J Endod 2002; 28: 105-107.

30. Yared G M, Bou Dagher FE, Machtou P. Cyclic fatigue of Profile rotary instruments after simulated clinical use. Int Endod J 1999; 32: 115-119.

31. Yared G M, Bou Dagher FE, Machtou P. Cyclic fatigue of ProFile rotary instruments after clinical use. Int Endod J 2000; 33: 204-207.

32. Arens F C, Hoen M M, Steiman H R, Dietz G C, Jr. Evaluation of single-use rotary nickel-titanium instruments. J Endod 2003; 29: 664-666.

33. Cheung G S, Peng B, Bian Z, Shen Y, Darvell B W. Defects in ProTaper S1 instruments after clinical use: fractographic examination. Int Endod J 2005; 38: 802-809.

34. Hilt B R, Cunningham C J, Shen C, Richards N. Torsional properties of stainless-steel and nickeltitanium files after multiple autoclave sterilizations. J Endod 2000; 26: 76-80.

35. Silvaggio J, Hicks M L. Effect of heat sterilization on the torsional properties of rotary nickel-titanium endodontic files. J Endod 1997; 23: 731-734.

36. Canalda-Sahli C, Brau-Aguade E, Sentis-Vilalta J. The effect of sterilization on bending and torsional properties of K-files manufactured with different metallic alloys. Int Endod J 998; 31: 48-52.

37. Viana A C, Gonzalez B M, Buono V T, Bahia M G. Influence of sterilization on mechanical properties and fatigue resistance of nickel-titanium rotary endodontic instruments. Int Endod J 2006; 39: 709-715.

38. Sattapan B, Palamara J E, Messer H H. Torque during canal instrumentation using rotary nickeltitanium files. J Endod 2000; 26: 156-160.

39. Martin B, Zelada G, Varela P, Bahillo J G et al. Factors influencing the fracture of nickeltitanium rotary instruments. Int Endod J 2003; 36: 262-266.

40. Li U M, Lee B S, Shih C T, Lan W H, Lin C P. Cyclic fatigue of endodontic nickel titanium rotary instruments: static and dynamic tests. J Endod 2002; 28: 448-451.

41. Karagoz-Kucukay I, Ersev H, Engin-Akkoca E, Kucukay S, Gursoy T. Effect of rotational speed on root canal preparation with Hero 642 rotary $\mathrm{Ni}-\mathrm{Ti}$ instruments. J Endod 2003; 29: 447-449.

42. Kuhn G, Tavernier B, Jordan L. Influence of structure on nickel-titanium endodontic instruments failure. J Endod 2001; 27: 516-520.

43. Alapati S B, Brantley W A, Svec T A, Powers J M et al. SEM observations of nickel-titanium rotary endodontic instruments that fractured during clinical use. J Endod 2005; 31: 40-43.

44. Herold K S, Johnson B R, Wenckus C S. A scanning electron microscopy evaluation of microfractures, deformation and separation in EndoSequence and Profile nickel-titanium rotary files using an extracted molar tooth model. J Endod 2007; 33: 712-714.

45. Berutti E, Negro A R, Lendini M, Pasqualini D. Influence of manual preflaring and torque on the failure rate of ProTaper rotary instruments. J Endod 2004; 30: 228-230.

46. Schrader C, Peters $O A$. Analysis of torque and force with differently tapered rotary endodontic instruments in vitro. J Endod 2005; 31: 120-123.

47. Darabara M, Bourithis L, Zinelis S, Papadimitriou G $D$. Susceptibility to localized corrosion of stainless steel and NiTi endodontic instruments in irrigating solutions. Int Endod J 2004; 37: 705-710.

48. Stokes $O$ W, Fiore P M, Barss J T, Koerber A, Gilbert $J \mathrm{~L}$, Lautenschlager E P. Corrosion in stainless-steel and nickel-titanium files. J Endod 1999; 25: 17-20.

49. Berutti E, Angelini E, Rigolone M, Migliaretti G, Pasqualini D. Influence of sodium hypochlorite on fracture properties and corrosion of ProTaper Rotary instruments. Int Endod J 2006; 39: 693-699.

50. Alapati S B, Brantley W A, Svec T A, Powers J M et al. Proposed role of embedded dentin chips for the clinical failure of nickel-titanium rotary instruments. J Endod 2004; 30: 339-341. 